\title{
Endocrine Disruptors, Obesity, and Cytokines - How Relevant Are They to PCOS?
}

\author{
Markéta ŠIMKOVÁ ${ }^{1,2}$, Jana VÍTKU' ${ }^{1}$, Lucie KOLÁTOROVÁ ${ }^{1}, J_{a n a}$ VRBÍKOVÁ ${ }^{1}$, \\ Michala VOSÁTKOVÁ ${ }^{1}$, Josef VČELÁK ${ }^{1}$, Michaela DUŠKOVÁ ${ }^{1,3}$
}

${ }^{1}$ Institute of Endocrinology, Prague, Czech Republic, ${ }^{2}$ University of Chemistry and Technology, Prague, Czech Republic, ${ }^{3}$ Department of Medicine Strahov, General University Hospital, Prague, Czech Republic

Received May 19, 2020

Accepted May 29, 2020

\section{Summary}

As environmental and genetic components contribute to the PCOS expression, we compared levels of endocrine disruptors, steroid hormones, cytokines, and metabolic parameters in twenty healthy, nine normal-weight PCOS women, and ten obese PCOS women. Steroid hormones, bisphenols (BPA, BPS, BPF, BPAF) and parabens (methyl-, ethyl-, propyl-, butyl-, benzyl-parabens) were measured by liquid chromatography-tandem mass spectrometry. Differences between the groups were assessed using the Mann-Whitney $\mathrm{U}$ test. Spearman correlation coefficients were calculated for the individual parameters relationship. Significantly higher levels of BPA, anti-Müllerain hormone, lutropine, lutropine/folitropine ratio, testosterone, androstenedione, $7 \beta-O H$-epiandrosterone, and cytokines (IL-6, VEGF, PDGF-bb), were found in normal-weight PCOS women compared to controls. Between normal-weight and obese PCOS women, there were no differences in hormonal, but in metabolic parameters. Obese PCOS women had significantly higher insulin resistance, fattyliver index, triglycerides, cytokines (IL-2, IL-13, IFN- - ). In healthy, but not in PCOS, women, there was a positive correlation of BPA with testosterone, SHBG with lutropine, and folitropine, while testosterone negatively correlated with SHBG. In obese women with PCOS, insulin resistance negatively correlated with SHBG and estradiol. No differences were observed in the paraben exposure. Levels of BPA were higher in PCOS women, indicating its role in the etiology. Obesity significantly worsens the symptoms.

\section{Key words}

Obesity - Bisphenols • Parabens - Cytokines • Liquid Chromatography-mass spectrometry

\section{Corresponding authors}

M. Šimková, Institute of Endocrinology, Národní 8, Prague, 116 94, Czech Republic. E-mail: msimkova@endo.cz

M. Dušková, Institute of Endocrinology, Národní 8, Prague, 116 94, Czech Republic. E-mail: mduskova@endo.cz

\section{Introduction}

Polycystic ovary syndrome (PCOS), a complex and heterogeneous disorder with a prevalence of approximately $5-10 \%$ of premenopausal women, is considered one of the leading endocrinopathy in women (Asuncion et al. 2000, Azziz et al. 2004, Franks 1995).

In 1990, the National Institute of Health, based on a consensus questionnaire of the attendees, put forward the following diagnostic criteria: the presence of clinical and/or biochemical hyperandrogenism and oligo/amenorrhea with anovulation (Zawadzki and Dunaif 1992). Later in 2003, the diagnostic criteria have been expanded by the addition of polycystic ovarian morphology seen at the ultrasound, the Rotterdam criteria were stated. According to them, the PCOS diagnosis requires meeting two of the three criteria mentioned above (Rotterdam ESHRE/ASRM-Sponsored PCOS Consensus Workshop Group 2004). The Androgen Excess Society has proposed a new set of diagnostic criteria in 2006. It considers androgen excess as a critical element in the development and pathogenesis of PCOS that should be present and accompanied by oligomenorrhea, polycystic ovarian morphology, or both (Azziz et al. 2006). Although there is still an intense 
debate about the appropriateness of proceedings under the Rotterdam criteria, as they are based on expert meetings rather than evidence-based treatment guidelines, they are used by the wide range of medical professionals and researchers (Wang and Mol 2017).

PCOS is usually accompanied by metabolic, reproductive, and neuroendocrine derangements. Hence there is a high predisposition to developing type 2 diabetes mellitus, atherogenic dyslipidemia, cardiovascular diseases, and reproductive disorders (Legro 2003, Legro et al. 1999). Metabolic syndrome, hyperinsulinemia, and peripheral insulin resistance, which occurs partly independently on body weight, although not confirmed by all studies, are among the many hallmarks of PCOS (Dunaif 1997). It is proven that the risk of metabolic disorders development and obesity increases with the defects in insulin action and secretion (Ehrmann 2005). Furthermore, obesity has a detrimental impact on the ovulatory process, where insulin resistance and compensatory hyperinsulinemia seem to play a vital role in major pathophysiologic mechanisms of reproductive disorders by directly affecting the insulinresistant PCOS ovary (Palioura et al. 2014).

Another distinctive feature is slightly enlarged ovaries with numerous antral follicles, which are exceeded by 2 - to 3 -fold that of normal ovaries causing irregular ovulation and oligo-/amenorrhea that may lead to conceiving difficulties (Hughesdon 1982, Webber et al. 2003). Polycystic ovaries are also characterized by the excess of androgen secretion by ovarian theca cells, which remain the primary source of hyperandrogenism (Cadagan et al. 2016, Nelson et al. 2001). A correlation of increased level of androgen with anti-Müllerian hormone $(\mathrm{AMH})$, intra-ovarian regulatory factor secreted by granulosa cell, was found (La Marca et al. 2004, Pigny et al. 2006). Serum levels of AMH in PCOS women are 2- to 3-fold higher than in ovulatory women with normal ovaries (Laven et al. 2004). Thus not only theca cells but granulosa cells are believed to modulate follicular steroidogenesis as well (Diamanti-Kandarakis and Piperi 2005).

In PCOS, persistently increased gonadotropinreleasing hormone $(\mathrm{GnRH})$ pulse frequency causing elevated luteinizing hormone (LH) secretion is typical, while the plasma level of follicle-stimulating hormone (FSH) is relatively decreased (McCartney et al. 2002). Furthermore, decreased sensitivity of the GnRH pulse generator to inhibition by progesterone was revealed. As a result, the elevated LH levels promote the increased androgen production from theca cells, whereas subsequent aromatization to estrogens by the action of FSH, which levels are lower, on granulosa cells is reduced. Thus a 'vicious circle' of hyperandrogenemia is created (Burt Solorzano et al. 2012).

Its underlying causes remain uncertain, but they are likely to be both genetic and environmental/ nutritional. Such diverseness of clinical manifestations of the syndrome evokes the possibility that several etiological factors synergistically contribute to the final PCOS phenotype (Diamanti-Kandarakis 2008). A particular emphasis has been placed on geographic location, ethnic origin, lifestyle, and environmental factors (Wijeyaratne et al. 2011). The role of the environment, particularly endocrine-disrupting chemicals (EDs) in the pathomechanisms of PCOS, has been much discussed recently.

EDs belong to heterogenic group of molecules, either natural or synthetic origin, with the ability to interfere with the endocrine system (DiamantiKandarakis et al. 2009). They can affect hormone biosynthesis, alter their both genomic and non-genomic effects, mechanisms of control and regulation, as well as epigenetic manifestations (Kolatorova Sosvorova et al. 2017). EDs can be found in several everyday-life products (e.g. plastic bottles, cosmetics, metal food cans, flame retardants, detergents, food, toys, and pesticides) and enter an organism by the intake of contaminated food and fluids, breathing contaminated air and by transdermal absorption (Darbre 2015).

One of the most widely discussed and abundant EDs is bisphenol A (BPA). Release of bisphenols from polycarbonates, epoxy resins, food and cosmetics packaging, and even dental composite materials has been discussed (Simkova et al. 2020). Its phenolic structure allows BPA to interact with estrogen receptors and thus affect hormonal homeostasis via a combination of agonistic and/or antagonistic actions depending on the target tissue. Nevertheless, the interaction of BPA with the androgen, the pregnane $\mathrm{X}$, the thyroid, and the glucocorticoid receptors were described (Ehrlich et al. 2014, Welshons et al. 2006, Žalmanová et al. 2016). Therefore, the use of BPA has been limited, which leads to its replacement in some products by its structural analogs, e.g. bisphenol S (BPS), bisphenol F (BPF), and bisphenol AF (BPAF). However, comparable endocrinedisruptive effects were observed in these alternative bisphenols, as the metabolism and mechanism of action are similar to BPA (Eladak et al. 2015, Rochester and 
Bolden 2015). Since BPA possess the ability of interaction with estrogen receptors, several groups focused on its role in female fertility. The serum concentration of BPA is elevated in PCOS and correlates with androgen levels (Kandaraki et al. 2011, Takeuchi et al. 2004). The data suggest that reproductive function is disturbed directly at the ovary level by affecting ovarian steroid hormone production and the maturation of the follicle or indirectly by interfering with the hypothalamic-pituitary axis (Palioura and DiamantiKandarakis 2015).

As mentioned, the human body faces the action of several agents with endocrine-disruptive properties. The so-called 'cocktail effect' from the addition or multiplication of each ED arises and may amplify the risks. A large number of personal care products, foods, and pharmaceuticals contain mixtures of bisphenols, parabens, and other EDs. Parabens, esters of p-hydroxybenzoic acid, are used as antimicrobial agents and preservatives. In addition to the estrogenic effect, several parabens also possess anti-androgenic activity as they can bind androgen receptors and thus inhibit testosterone-induced transcription (Bledzka et al. 2014). Methylparaben (MP) and propylparaben (PP), accompanied by ethylparaben (EP), butylparaben (BP), and benzylparaben (benzylP) are among the most commonly used. In vivo studies indicate that parabens may disrupt reproduction, development, and homeostasis. In humans, they have been detected in serum, urine cord blood, meconium, milk, amniotic fluid, and placental tissue (Azzouz et al. 2016, Baker et al. 2020, Kolatorova Sosvorova et al. 2017, Pollack et al. 2020, Vela-Soria et al. 2014, Vitku et al. 2018a). Relevant associations of MP and hormones affecting metabolic health and energy were observed, indicating is obesogenic potential. Associations of methylparaben and hormones affecting energy balance and metabolic health were observed, indicating its obesogenic potential (Kolatorova et al. 2018).

As obesity is associated with low-grade inflammation and increased inflammatory cytokines, searching for potential correlation in PCOS women is crucial for a deeper understanding of biochemical mechanisms. Several groups have indicated elevated levels of specific cytokines in PCOS women, pointing out that chronic low-grade inflammation may affect the development of ovarian dysfunction and metabolic derangement (Amato et al. 2003, Ebejer and CallejaAgius 2013, González 2012, Xiong et al. 2011).
However, the studies are still not in agreement with which all they are and play a central role in the inflammation. The question is if the principal role in lowgrade inflammation is due to obesity only or also to PCOS. We investigate the associations between hormonal status, ED exposition and cytokines of PCOS women, and the role of obesity.

\section{Materials and Methods}

\section{Chemicals and reagents}

The steroids estrone (E1), 17 $\beta$-estradiol (E2), estriol (E3), and deuterated internal standards of estrone (d4E1) and estriol (d4E3) were obtained from Steraloids (Newport, USA). Reference standards of MP, EP, PP, BP, benzylP, BPA, BPS, BPF, BPAF as well as deuterated standards of BPA(d16BPA) and E2 (d3E2) were purchased from Sigma Aldrich (St. Louis, MO, USA). Chemicals such as $99.9 \%$ tert-butyl methyl ether (MTBE), acetone, sodium bicarbonate, sodium hydroxide, and dansyl chloride were from Sigma Aldrich (St. Louis, MO, USA). Internal standards of EP (d4EP) and BP (d4BP) were obtained from EQ Laboratories GmBH (Ausburg, Germany) and internal standards of further parabens (d4MP and d4PP) were from Chiron (Trondheim, Norway). The deuterated standard of BPS (d4BPS) was prepared as described in our previous paper (Kolatorova Sosvorova et al. 2017). Methanol and water were of LC-MS grade and purchased from Merck AG (Darmstadt, Germany). The immunoanalytical kit for the determination of 27 cytokines (FGF basic, eotaxin, G-CSF, GM-CSF, IFN- $\gamma$, IL-1 $\beta$, IL-1ra, IL-2, IL-4, IL-5, IL-6, IL-7, IL-8, IL-9, IL-10, IL-12 (p70), IL-13, IL-15, IL-17A, IP-10, MCP-1 (MCAF), MIP-1 $\alpha$, MIP-1 $\beta$, PDGF-BB, RANTES, TNF- $\alpha$, VEGF) \#M500KCAF0Y Bio-Plex Pro ${ }^{\mathrm{TM}}$ Human Cytokine 27-plex Assay, was purchased from Bio-Rad Laboratories, Inc. (Hercules, California).

\section{Study population}

This study consisted of 19 women with PCOS and 20 healthy controls. All patients met NIH 1990 and ESHRE criteria. The patients were selected from 75 women suspected for PCOS, their condition and correct diagnosis were critically evaluated by two experts independently. Women with PCOS were further divided into two groups according to body mass index (BMI). Nine of them, forming the 'normal-weight PCOS' group, had a BMI $21.4 \pm 3.2(\mathrm{BMI} \pm \mathrm{SD})$, the remaining ten 
formed 'obese PCOS' group with BMI 35 \pm 2.7 . The control group had a BMI 22.2 \pm 2.4 . Normal-weight PCOS women were $28.9 \pm 7.4$ years old, obese PCOS women $29.5 \pm 5.8$ years old, and healthy controls $29.9 \pm 6.4$ years old.

Glycated hemoglobin levels, as well as liver function profile, were normal in all women. Most of the women were non-smokers; the proportion of smokers and ex-smokers was the same in all groups. The history of hormonal contraceptive use was the same between groups; none of the women had used it in the last five years. They had no nutritional disorders, excessive alcohol consumption, oncologic or autoimmune disease. None of the women was undergoing any treatment that might interfere with steroid hormone metabolism (corticosteroids, including topical or inhaled, hormonal contraception, insulin sensitizers, hypolipidemics, antidepressives, antiepileptics, neuroleptics, antihypertensives). The probands enrolled in the study as healthy control showed no signs of hyperandrogenemia and had a regular menstrual cycle. The study was approved by the Ethical Committee of the Institute of Endocrinology. All probands signed the informed consent with the use of biological materials for research. The study was conducted following with the Declaration of Helsinki (2000) of the World Medical Association.

\section{Sample collection}

Blood samples were drawn between 7 and 9 a.m. with concerning steroid hormone circadian rhythm (Duskova et al. 2020, Duskova et al. 2018). On the day of collection, all women were in the follicular phase, between day one and day five of the menstrual cycle. The plasma was used for assessment of biochemical parameters of liver and kidney function (alanine transaminase (ALT), aspartate transaminase (AST), gamma-glutamyltransferase (GGT), albumin, metabolic parameters (C-peptide, cholesterol, low-density lipoprotein (LDL) cholesterol, high-density lipoprotein (HDL) cholesterol, insulin, glucose, triglycerides), gonadotropins (LH, FSH), anti-Müllerian hormone $(\mathrm{AMH})$ and cytokines. Further, steroid hormones, bisphenols (BPA, BPS, BPF, BPAF), and parabens (MP, EP, PP, BP, benzylP) were analyzed. All samples were stored at $-20{ }^{\circ} \mathrm{C}$ until analysis.

All steps in sample collection and subsequent analysis were performed with glass equipment (glass tubes, Pasteur pipettes, glass syringes, etc.) to avoid bisphenol contamination. The only plastic that the blood came into contact was collection tubes, and it was found that there is no leakage (Vitku et al. 2015). Furthermore, steps have been taken to prevent paraben contamination, including washing of all reusable laboratory glassware in ultrapure water, acetonitrile, and methanol p.a. and heating for $8 \mathrm{~h}$ at $400{ }^{\circ} \mathrm{C}$. More information dealing with possible contamination can be found in the study of Kolatorova Sosvorova et al. (2017).

\section{Analyses of biochemical markers and cytokines}

The plasma levels of the following biochemical markers were measured spectrophotometrically using Cobas ${ }^{\circledR} 6000$ modular analyzer (Roche, Manheim, Germany). The concentration of glucose was measured using an enzymatic reference method with hexokinase. Triglycerides, LDL, HDL, cholesterol, and GGT levels were analyzed using an enzymatic colorimetric method. According to The International Federation of Clinical Chemistry (IFCC), an enzymatic method was used to determintate AST and ALT. Using a Bromcresol Green Method, the albumin levels were measured. Electro-chemiluminescence immunoassay, performed on Cobas ${ }^{\circledR} 6000$, was used to measure $A M H$, insulin, C-peptide, LH, and FSH. Glycated hemoglobin (HbA1c) was measured using an ion-exchange high-performance liquid chromatography (HPLC) method (Adams A1c HA 8180V, Arkray, Minneapolis, Minnesota, USA). The analyses of 27 human cytokines were performed on Multiples immunoanalytic xMAP technology (Luminex Corporation) using the kit \#M500KCAF0Y Bio-Plex Pro $^{\mathrm{TM}}$ Human Cytokine 27-plex Assay employing the Bio-Plex ${ }^{\circledR} 200$ system (both Bio-Rad Laboratories, Inc.).

Homa-IR index, a Homeostatic Model Assessment for Insulin Resistance, was determined from glucose and insulin levels according to Matthews et al. (1985). Fatty liver index (FLI) was calculated from body weight, body height, waist circumference, triglycerides, and GMT levels according to Bedogni et al. (2006).

Determination of steroid hormones, bisphenols and parabens

The plasma levels of unconjugated steroids, bisphenols, and parabens were measured by already validated and published methods (Kolatorova Sosvorova et al. 2017, Vitku et al. 2015). Briefly, $500 \mu \mathrm{l}$ of plasma sample was spiked with a internal standard mixture. Each sample was diluted with $500 \mu \mathrm{l}$ of physiological solution ( $0.9 \%$ sodium chloride), and liquid-liquid extraction using $99.9 \%$ MTBE ( $2 \mathrm{ml}, 1 \mathrm{~min})$ was performed. The 
organic layer was transferred into another glass tube and evaporated until dryness by vacuum concentrator $\left(55^{\circ} \mathrm{C}\right)$. Consequently, a derivatization reaction was carried out; a volume of $50 \mu$ l bicarbonate buffer (100 mM, pH 10.5) and $50 \mu \mathrm{l}$ of dansyl chloride in acetone $(1 \mathrm{mg} / \mathrm{ml})$ was added to the dry residue, shortly vortexed and incubated in a heat block $\left(60^{\circ} \mathrm{C}\right)$ for $5 \mathrm{~min}$. Samples were subsequently let to cool down to room temperature and evaporated into dryness by vacuum concentrator again. The residues were redissolved in $300 \mu \mathrm{l}$ methanol. The volume of $50 \mu \mathrm{l}$ of this mixture together with $50 \mu \mathrm{l}$ of $10 \mathrm{mM}$ ammonium formate in ultrapure water was transferred into the vial with a glass insert and subsequently analyzed. The injection volume was $50 \mu \mathrm{l}$.

LC-MS/MS analysis was performed on ultrahigh performance liquid chromatograph Eksigent ultraLC 110 system (Redwood City, CA, USA) connected to API 3200 (Sciex, Concord, Canada) triple quadrupole mass spectrometer. Chromatographic separation was performed on the Kinetex C18 column (10 mm x $3 \mathrm{~mm}$; $1.7 \mu \mathrm{m}$ particles) from Phenomenex (Torrance, CA, USA) supplemented with the corresponding guard. All details regarding chromatographic and mass spectrometry conditions can be found in the articles mentioned above.

Levels of free and bioavailable testosterone were calculated from testosterone, albumin and SHBG concentrations using a calculator developed at the Hormonology Department of University Hospital of Ghent, Belgium (Vermeulen et al. 1999).

\section{Statistical analysis}

According to Hornung and Reed (1990), the data under the limit of detection were replaced by LOQ $/ \sqrt{ } 2$. Since a majority of the data had a non-Gaussian distribution, the Mann-Whitney $U$ test was performed to compare 'normal-weight PCOS' and 'control' groups and 'normal-weight PCOS' and 'obese PCOS'. A Spearman correlation was subsequently used to determine a correlation between steroid hormones, EDs, and cytokines within each of the groups. The statistical testing was performed in SciPy, an open-source scientific computing library for the Python programming language, and Statistica 13 software (Tibco Software Inc., Palo Alto, CA, USA). For a data visualization, Seaborn, a Python data visualization library, was used.

\section{Results}

In our study, we focused on the hormonal, metabolic, pro-inflammatory status, and exposure to EDs of obese and normal-weight women with PCOS. We compared normal-weight PCOS women to healthy controls and subsequently normal-weight PCOS to obese ones. Hormonal levels are shown in Table 1, metabolic parameters in Table 2, and exposure to bisphenols and parabens are in Table 3. Data are shown separately for each group.

At the hormonal level, normal-weight PCOS women had significantly higher AMH $(p=0.004), \mathrm{LH}$ $(p=0.003), \mathrm{LH} / \mathrm{FSH}$ ratio $(0.003)$, testosterone $(\mathrm{p}=0.011)$, free testosterone $(\mathrm{p}=0.013)$, bioavailable testosterone $(\mathrm{p}=0.012), \quad$ androstenedione $\quad(\mathrm{p}=0.016), \quad 7 \beta-\mathrm{OH}-$ epiandrosterone $(\mathrm{p}=0.006)$ compared to healthy controls. As for hormones, there were no significant differences between normal-weight and obese women with PCOS. Compared with obese, normal-weight PCOS women had significantly higher levels of SHBG $(p=0.005)$. While in healthy controls, SHBG positively correlated with LH and FSH $(r=0.613, p<0.01 ; r=0.623, p<0.005$; respectively), no such correlations were found in any of group of PCOS. The LH/FSH ratio positively correlated with $\mathrm{AMH}$ levels in all of the groups.

There were no differences in metabolic parameters between normal-weight PCOS and healthy controls. Obese PCOS women had significantly higher HOMA-IR $(p=0.005)$, fatty liver index $(p=0.003)$, triglycerides $(p=0.014)$, and significantly lower HDL cholesterol $(p=0.01)$. In obese PCOS women, HOMA-IR negatively correlated with SHBG $(\mathrm{r}=-0.745, \mathrm{p}<0.02)$ as well as with estradiol $(r=-0.709, p<0.02)$.

The exposure of BPA was significantly higher in normal-weight PCOS women than in healthy controls $(p=0.042)$. There was no difference between normalweight and obese PCOS women. While BPA was abundant in all of the samples (in $70 \%$ of healthy controls, $100 \%$ of normal-weight PCOS and $90 \%$ of obese women) and BPS was also often detected (in $25 \%$ of healthy controls, $33 \%$ of normal-weight PCOS and $40 \%$ of obese women), BPF and BPAF were not found in any samples. In healthy controls, BPA positively correlated with free testosterone and testosterone ( $\mathrm{r}=0.556 \mathrm{p}<0.05 ; \mathrm{r}=0.662, \mathrm{p}<0.003$, respectively) while in PCOS women, no correlation was found. As parabens are used in a mixture rather than separately, we focused only on the sum of parabens. No significant differences were registered between each group, and the total exposure was low. 
Table 1. Comparison of plasma hormone levels, plasma EDs levels, metabolic parameters, and cytokine levels in control group, normalweight PCOS and obese PCOS.

\begin{tabular}{|c|c|c|c|}
\hline Analyte & Controls & Normal-weight PCOS & Obese PCOS \\
\hline$A M H[n g / m l]$ & $2.69(2.26,3.5)$ & $7.59(5.09,10.95)$ & $5.68(5.05,6.11)$ \\
\hline$L H[I U / l]$ & $5.80(4.85,7.3)$ & $9.6(7.3,12.1)$ & $6.35(4.53,8.03)$ \\
\hline FSH [IU/l] & $5.80(4.75,8.4)$ & $7.2(5.5,7.9)$ & $5.75(5.2,6.08)$ \\
\hline$L H / F S H$ & $0.857(0.786,1.14)$ & $1.56(1.26,2.21)$ & $1.29(1.02,1.77)$ \\
\hline Free Testosterone [nmol/l] & $0.009(0.007,0.012)$ & $0.019(0.01,0.023)$ & $0.021(0.015,0.029)$ \\
\hline Free Testosterone [\%] & $1.14(0.91,1.32)$ & $1.31(1.01,1.5)$ & $1.93(1.61,2.21)$ \\
\hline Bioavailable T [nmol/l] & $0.219(0.17,0.287)$ & $0.459(0.269,0.645)$ & $0.508(0.365,0.703)$ \\
\hline Bioavailable T [\%] & $29.5(25.8,33.4)$ & $29.2(25.3,38.2)$ & $47.4(41,54.3)$ \\
\hline Testosterone $[\mathrm{nmol} / \mathrm{l}]$ & $0.863(0.66,0.97)$ & $1.37(1.12,1.61)$ & $1.20(0.84,1.41)$ \\
\hline SHBG [nmol/l] & $67.6(51.2,80.2)$ & $60.4(42.6,75.3)$ & $28(21.6,37.4)$ \\
\hline Cortisol [nmol/l] & $422(368,550)$ & $486(331,499)$ & $392(319,474)$ \\
\hline Cortisone [nmol/l] & $127(105,138)$ & $128(103,143)$ & $113(100,126)$ \\
\hline DHEA [nmol/l] & $23(19,32.2)$ & $28.5(19.9,48.6)$ & $32.8(26.3,49.4)$ \\
\hline Androstenedione [nmol/l] & $2.59(2.14,2.93)$ & $4.16(2.92,5.34)$ & $3.36(2.47,4.74)$ \\
\hline Pregnenolone [nmol/l] & $1.67(0.85,2.43)$ & $2.29(1.57,2.53)$ & $1.40(0.82,2.33)$ \\
\hline 17-OH-Preg [nmol/l] & $3.19(1.34,7.47)$ & $4.75(3.67,9.99)$ & $2.84(2.18,9.25)$ \\
\hline $7 \alpha-O H-D H E A[n m o l / l]$ & $1.86(1.28,2.62)$ & $3.23(1.94,3.81)$ & $2.31(1.98,2.86)$ \\
\hline $7 \beta-O H-D H E A[\mathrm{nmol} / \mathrm{l}]$ & $1.01(0.79,1.34)$ & $0.913(0.706,1.63)$ & $1.04(0.9,1.13)$ \\
\hline $7 \beta-O H-E p i A[n m o l / l]$ & $0.124(0.025,0.198)$ & $0.467(0.255,0.594)$ & $0.263(0.188,0.340)$ \\
\hline Estrone [nmol/l] & $0.027(0.027,0.045)$ & $0.062(0.027,0.092)$ & $0.134(0.113,0.143)$ \\
\hline Estradiol [nmol/l] & $0.062(0.034,0.145)$ & $0.089(0.049,0.112)$ & $0.12(0.07,0.136)$ \\
\hline Estriol [nmol/l] & $0.049(0.023,0.091)$ & $0.035(0.023,0.036)$ & $0.083(0.042,0.121)$ \\
\hline BPA [nmol/l] & $0.129(0.065,0.211)$ & $0.282(0.129,0.356)$ & $0.129(0.129,0.192)$ \\
\hline BPA occurrence \% & 70 & 100 & 90 \\
\hline BPS [nmol/l] & $0(0,0.078)$ & $0(0,0.155)$ & $0(0,0.155)$ \\
\hline BPS occurrence \% & 25 & 33 & 40 \\
\hline Sparabens [nmol/l] & $0(0,0.391)$ & $0.488(0,2.85)$ & $0(0,0)$ \\
\hline Sparabens occurrence \% & 30 & 56 & 10 \\
\hline Waist $[\mathrm{cm}]$ & $71(67.5,77)$ & $73.5(69.8,78.5)$ & $106(102,114)$ \\
\hline$B M I$ & $22.0(20.0,24.5)$ & $21.4(18.5,24.1)$ & $34.6(33,35.4)$ \\
\hline HOMA-IR & $1.23(0.91,1.61)$ & $1.67(1.37,2.39)$ & $3.72(3.01,5.66)$ \\
\hline$F L I$ & $3.5(3,7.75)$ & $6(3.5,7.75)$ & $82(68.3,93.8)$ \\
\hline Triglycerides [mmol/l] & $0.74(0.66,0.80)$ & $0.73(0.62,0.77)$ & $1.23(0.98,1.39)$ \\
\hline Cholesterol [mmol/l] & $4.32(4.08,5.31)$ & $4.39(4.24,4.62)$ & $4.23(4.03,5.33)$ \\
\hline LDL cholesterol [mmol/l] & $2.48(2.15,3.32)$ & $2.48(2.29,2.78)$ & $2.81(2.32,3.92)$ \\
\hline HDL cholesterol [mmol/l] & $1.82(1.74,2.09)$ & $1.81(1.59,2.07)$ & $1.27(1.11,1.50)$ \\
\hline$I L-2[\mathrm{pg} / \mathrm{ml}]$ & $18(11.9,22.8)$ & $12.5(9.27,19.8)$ & $22.2(20.1,29.3)$ \\
\hline$I L-6[\mathrm{pg} / \mathrm{ml}]$ & $23.1(11,42)$ & $56.7(30.2,118.9)$ & $82.1(51.5,155)$ \\
\hline$I L-13[\mathrm{pg} / \mathrm{ml}]$ & $7.38(5.46,9.99)$ & $5.82(4.85,7.07)$ & $8.85(6.92,10.8)$ \\
\hline$I F N-\gamma[\mathrm{pg} / \mathrm{ml}]$ & $19.9(12.8,35.7)$ & $13.4(9.72,18.6)$ & $32.8(24.5,41.3)$ \\
\hline$P D G F-b b[\mathrm{pg} / \mathrm{ml}]$ & $216(142,321)$ & $328(289,339)$ & $291(235,403)$ \\
\hline$V E G F[p g / m l]$ & $459(211,679)$ & $1028(811,1707)$ & $1120(869,1967)$ \\
\hline
\end{tabular}

Data are shown as medians with lower and upper quartiles (in parentheses) for each group. 
Table 2. Comparison of measured parameters in control group and normal-weight PCOS.

\begin{tabular}{|c|c|c|}
\hline Parameter & p-value & $\begin{array}{c}\text { Group with higher } \\
\text { concentration }\end{array}$ \\
\hline BPA & 0.042 & PCOS \\
\hline $\mathrm{AMH}$ & 0.004 & PCOS \\
\hline LH & 0.003 & PCOS \\
\hline LH/FSH & 0.003 & PCOS \\
\hline Testosterone & 0.011 & PCOS \\
\hline Free Testosterone & 0.013 & PCOS \\
\hline Bioavailable Testosterone & 0.012 & PCOS \\
\hline Androstenedione & 0.016 & PCOS \\
\hline $7 \beta-O H-E p i a n d r o s t e r o n e$ & 0.006 & PCOS \\
\hline IL-6 & 0.045 & PCOS \\
\hline VEGF & 0.030 & PCOS \\
\hline PDGF-bb & 0.020 & PCOS \\
\hline IL-1ra & 0.040 & control group \\
\hline$I L-7$ & 0.034 & control group \\
\hline$G-C S F$ & 0.036 & control group \\
\hline
\end{tabular}

Only parameters with the level of significance $p<0.05$ are shown. Cytokines, in which levels differ both PCOS groups with each other and normal-weight PCOS with controls, are in italics.

Table 3. Comparison of measured parameters in normal-weight PCOS and obese PCOS women.

\begin{tabular}{lcc}
\hline Parameter & p-value & $\begin{array}{c}\text { Group with higher } \\
\text { concentration }\end{array}$ \\
\hline BMI & 0.001 & obese PCOS \\
SHBG & 0.005 & normal-weight PCOS \\
HOMA-IR & 0.005 & obese PCOS \\
HDL cholesterol & 0.010 & normal-weight PCOS \\
Fatty liver index & 0.003 & obese PCOS \\
Triglycerides & 0.014 & obese PCOS \\
IL-2 & 0.030 & obese PCOS \\
IL-13 & 0.030 & obese PCOS \\
IFN- $\gamma$ & 0.004 & obese PCOS \\
IL-1ra & 0.041 & obese PCOS \\
IL-7 & 0.005 & obese PCOS \\
$G-C S F$ & 0.020 & obese PCOS \\
\hline
\end{tabular}

Only parameters with the level of significance $p<0.05$ are shown. Cytokines, which levels differ both in PCOS groups with each other and normal-weight PCOS with controls, are in italics.

The expression of cytokines differs slightly between healthy controls and normal-weight PCOS.
From 27 measured cytokines, there were only three of them exclusively higher in normal-weight PCOS women compared to healthy controls (namely, IL-6, VEGF, and PDGF-bb), and on the other hand, three of them higher in controls (IL-1ra, IL-7, G-CSF). Contrastly, in obese PCOS women compared to normal-weight ones, notable differences were observed. Of the following cytokines, all of their levels were higher in obese women, namely IL-2, IL-13, IFN- $\gamma$, IL-1ra, IL-7, G-CSF. P-values are shown in Table 2 and Table 3.

There was no correlation between EDs, and cytokines, EDs and metabolic parameters and cytokines, and metabolic parameters. Only three cytokines, IL-2, IL-4, IL-17, positively correlated with BMI in obese PCOS women.

Histograms showing the differences between groups in the levels of AMH, testosterone, and BPA are in Figure 1, histograms showing the differences between the groups in the level of HOMA-IR index, and Fatty Liver Index are in Figure 2.

\section{Discussion}

According to Stein and Leventhal, PCOS was described in 1935; however, the etiopathogenesis is still unclear until this time. The diagnostic criteria were developed during this period, emphasizing different aspects of PCOS. Many causes were discovered, but none was declared the principle. It could be concluded that the specific mixture of metabolic, hormonal, genetic and last but not least environmental factors are involved in the formation of PCOS (Fenichel et al. 2017). We focused on the environmental factors as one of the possible puzzles of the etiopathogenesis of PCOS. To the best of our knowledge, no study has yet focused on the association of metabolic and hormonal profile, BPA with its structural analogs (BPS, BPF, BPAF), parabens (MP, EP, $\mathrm{PP}, \mathrm{BP}$, benzylP) and cytokines in normal-weight and obese PCOS women.

We selected well-defined groups of normalweight and obese women with PCOS according to NIH 1990 and ESHRE criteria, and age-matched control group. This concept helps to focus on the parameters exclusively related to PCOS and discriminates the impact of obesity.

Firstly, we focused on the hormonal profile of PCOS. Besides the well-known hormonal characteristics (higher testosterone, androstenedione, $\mathrm{AMH}$ levels, and $\mathrm{LH} / \mathrm{FSH}$ ratio) we found significantly higher levels of 
$7 \beta-\mathrm{OH}$-epiandrosterone, which possess anti-estrogenic, anti-inflammatory, and neuroprotective effects (Vitku et al. 2018b). We suggest considering 73-OH- epiandrosterone, a metabolite of androgens, as a new steroid characteristic biomarker of PCOS women. This finding was to the date not described in PCOS women.

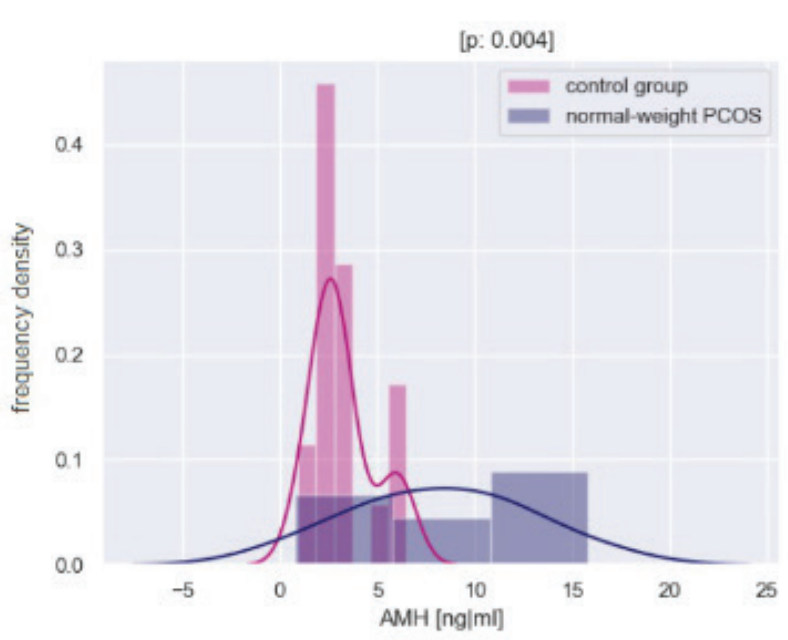

$\mathrm{AMH}$
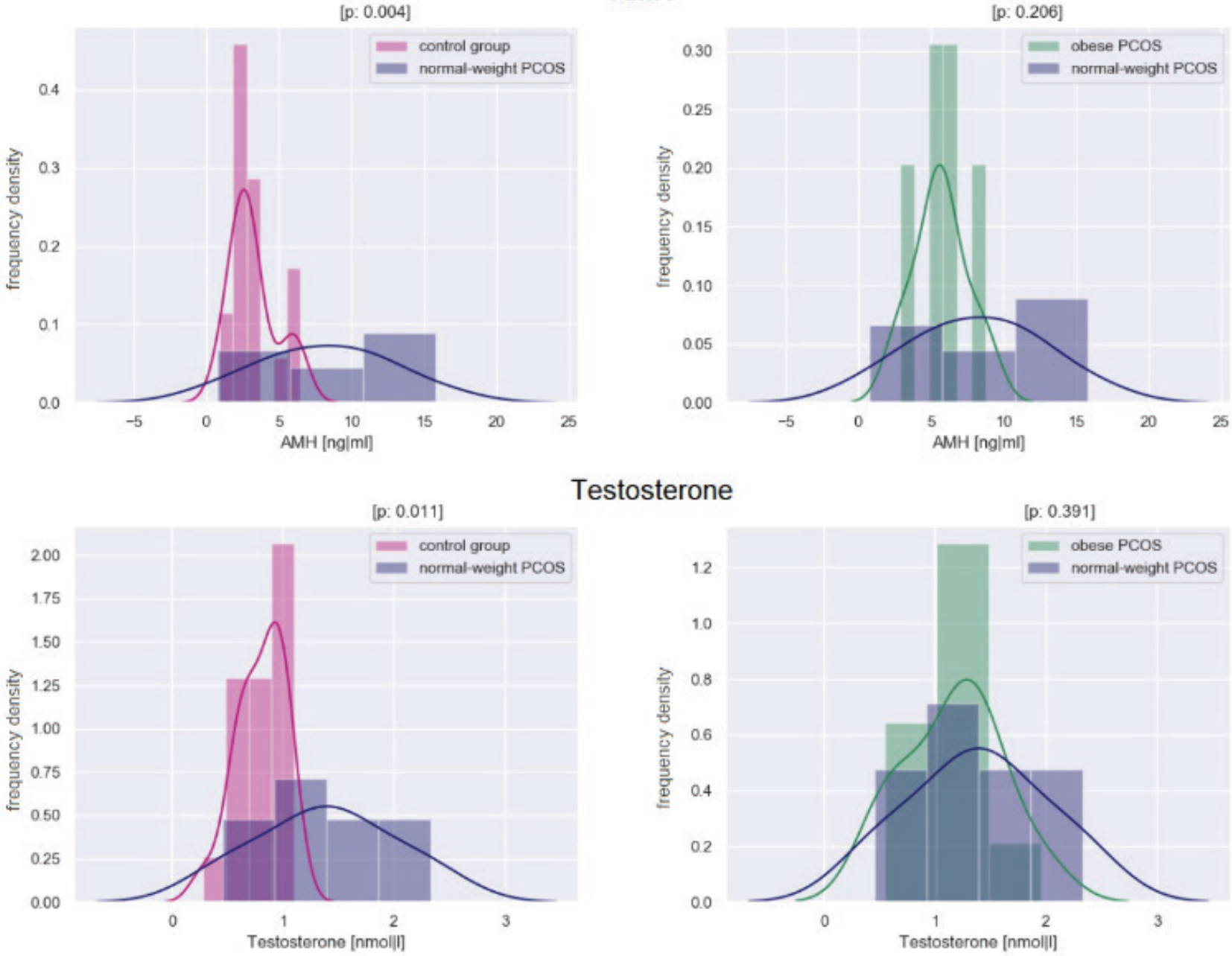

Testosterone
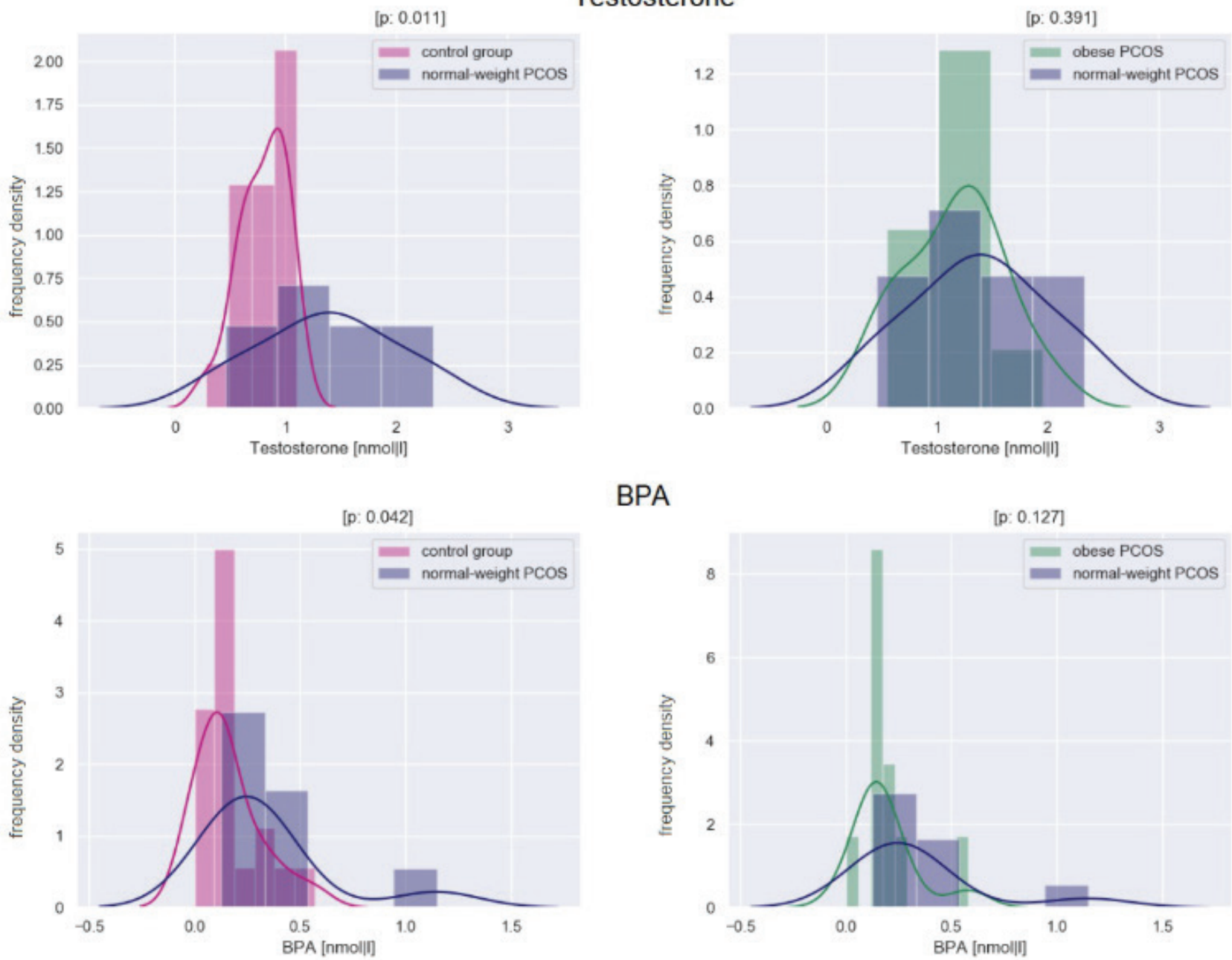

BPA

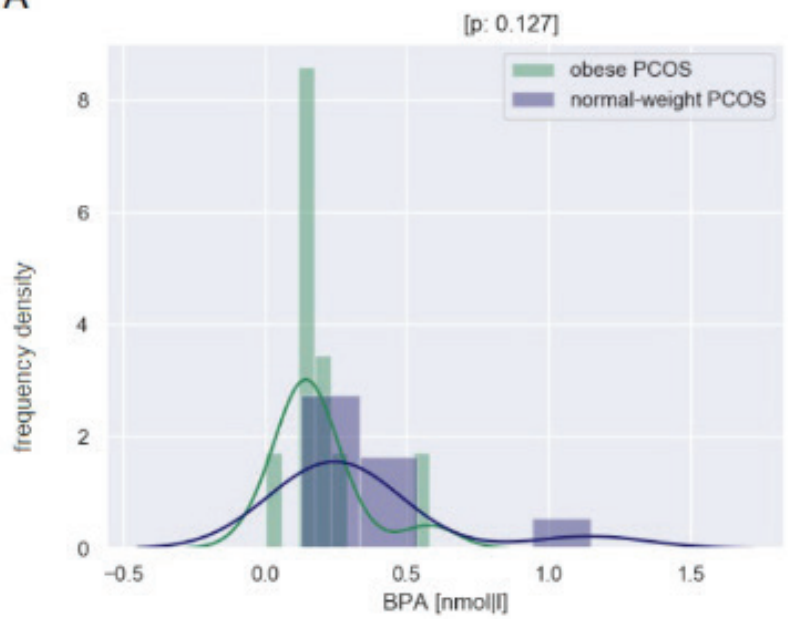

Fig. 1. Histograms showing the differences between groups in the levels of $A M H$, testosterone, and BPA. The $x$-axis shows the analyte concentration; the $y$-axis indicates the frequency density. The level of significance is provided as a $p$-value. A $p$-value<0.05 indicates a statistically significant difference. 


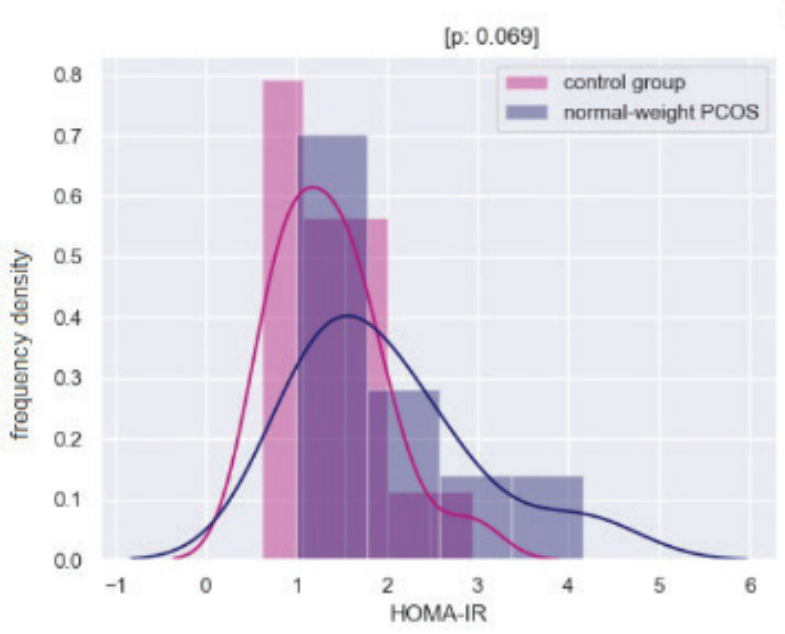

HOMA-IR
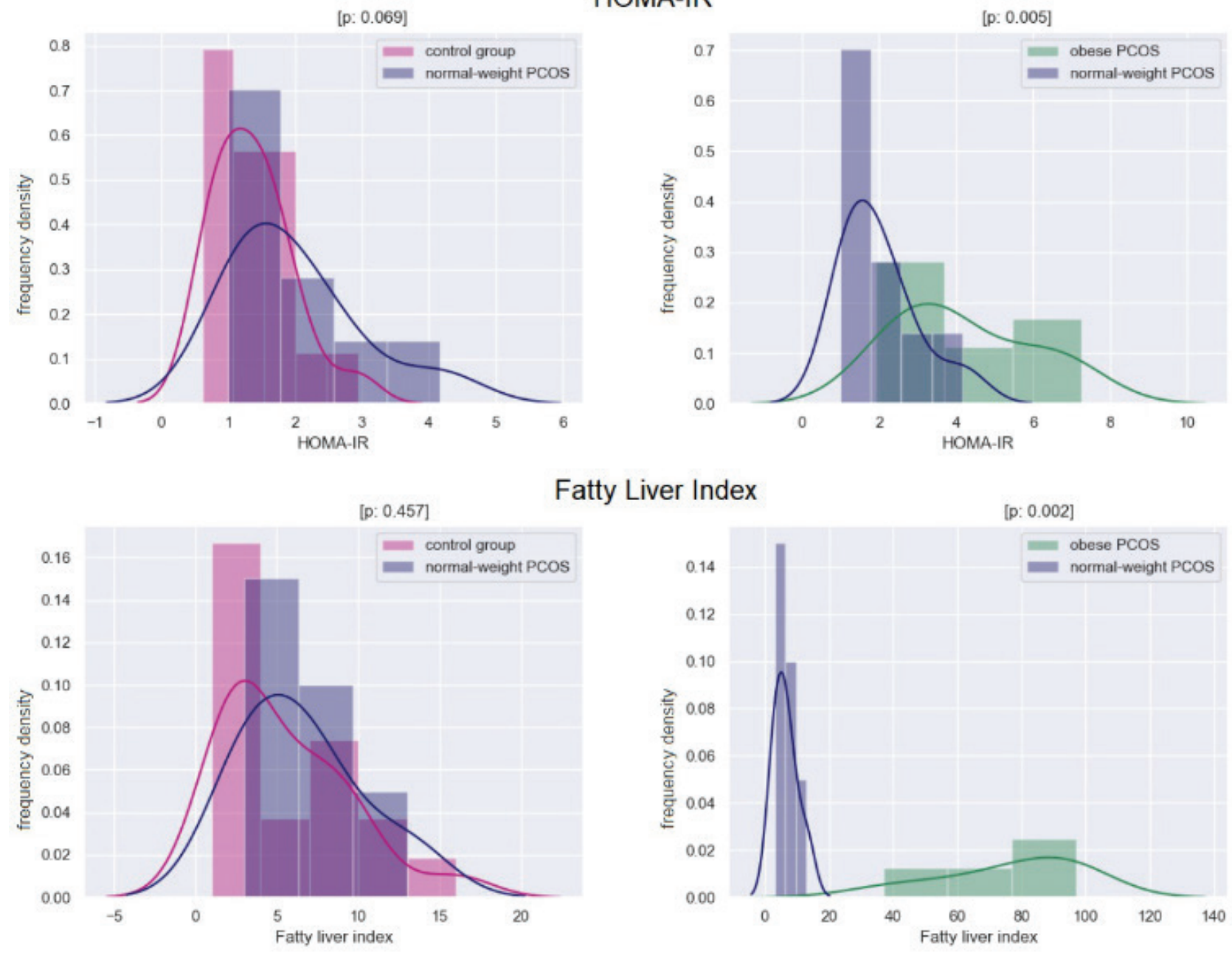

Fatty Liver Index

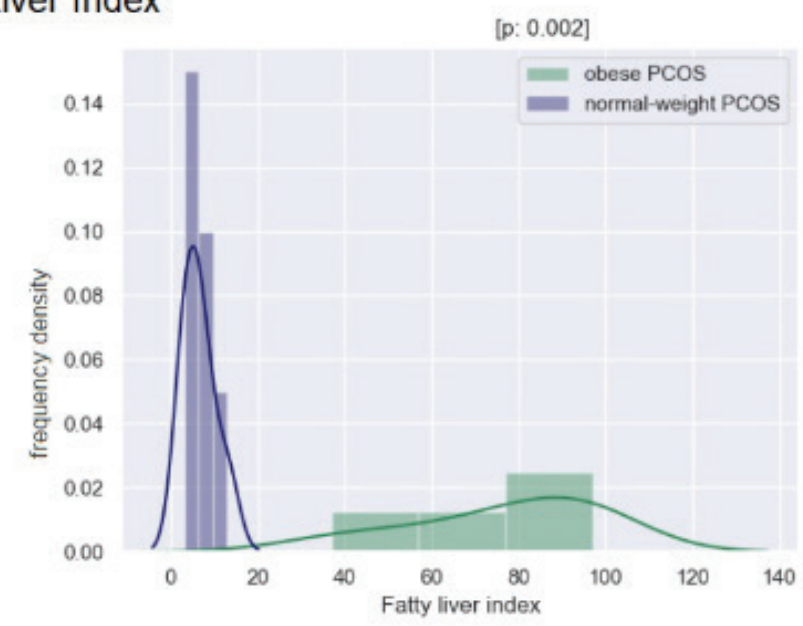

Fig. 2. Histograms showing the differences between groups in the levels of HOMA-IR index, and Fatty Liver Index. The $x$-axis shows the index value; the $y$-axis indicates the frequency density. The level of significance is provided as a $p$-value. A $p$-value $<0.05$ indicates a statistically significant difference.

We found the higher levels of BPA in PCOS patients compared to healthy controls, without differences between normal-weight and obese ones. Our results are in agreement with literature data from human studies as well as with animal models and in vitro studies (Akgul et al. 2019, Akin et al. 2015, Akin et al. 2014b, Akin et al. 2014a, Cunningham et al. 2016, Dominguez et al. 2008, Elmalid 2014, Hossein Rashidi et al. 2017, Kandaraki et al. 2011, Konieczna et al. 2018, Lazurova et al. 2018, Niemuth and Klaper 2018, Patisaul et al. 2014, Rutkowska et al. 2015, Takeuchi and Tsutsumi 2002, Takeuchi et al. 2004, Vagi et al. 2014, Vahedi et al. 2016, Wang et al. 2017, Yang et al. 2019, Zhou et al. 2016). These findings confirm that BPA could be one of the essential elements in the PCOS etiopathogenesis. It is known from the literature that the interaction between $\mathrm{BPA}$ and testosterone is complex. On the one hand, testosterone interacts with BPA metabolism by decreasing uridine diphosphatase- glucuronosyl transferase activity, which leads to increased levels of BPA. On the other hand, BPA interferes with testosterone metabolism firstly by inhibition of testosterone hydroxylases (2- and 6-hydroxylase), which are not that important in the degradation of testosterone as much as oxidoreductases, but still can play a role in its metabolism. Secondary by displacing testosterone on SHBG, which leads to the increase of circulating free androgen concentration (Palioura and Diamanti-Kandarakis 2013, Palioura et al. 2014). These interactions, especially the influence on binding protein, could explain our findings of the correlation between BPA exposure and testosterone only in a healthy control group, unlike in PCOS women, where the testosterone levels are high, thus a 'vicious circle' with BPA is formed.

As its structural analogs in the industry often replace $\mathrm{BPA}$, we also monitored the exposure to alternative bisphenols. We found only low levels of BPS, 
slightly more frequently in PCOS patients. If significant exposure to other alternative bisphenols in PCOS occurred, the same effect, as in the case of BPA, could be expected. To the best of our knowledge, there are no literature data focused on the exposition to alternative bisphenols in PCOS. As parabens play a role in obesity, we also followed the parabens exposition, which is very low and the same among all groups. It may be due to the reduced use of parabens in the industry in recent years We did not found any relationship to PCOS or obesity.

We found that already at the age of 30 , obese PCOS women suffer from insulin resistance, adverse lipid profiles, and high risk of fatty liver disease. Furthermore, we found higher cytokines levels in obese PCOS, which, in complexity, reflect activation and proinflammatory state. Contrarily, aged-matched normalweight PCOS women have retained insulin sensitivity, standard lipid profile, and very low risk of fatty liver disease, showing the same metabolic profile as healthy controls. The difference in cytokines between normalweight $\mathrm{PCOS}$ and control group were negligible. We found elevated levels of IL-6, VEGF, and PDGF-bb in normal-weight PCOS women compared to healthy controls in an agreement with literature data. These three cytokines could be one of the puzzles in the etiopathogenesis of PCOS (Martínez-Reyes et al. 2018, Schmidt et al. 2015). Findings in obese PCOS women (insulin resistance, lousy lipid profile, risk of fatty liver disease, and proinflammatory state) compared to normalweight PCOS women, which have very similar metabolic profile as healthy control, are confirmation of how obesity could obscure the searching of PCOS etiopathogenesis.

In the PCOS etiopathogenesis searching, it is necessary to mention that several ancient medical reports from Hippocrates, Ephaeseus, and Maimonides described similar disorders like PCOS, and in many different geographical regions of the world, PCOS has the same prevalence (Fenichel et al. 2017). It means that PCOS, despite evolutionary pressure and geographical influence, is constant and stable in humans. This raised a question of the evolutionary paradox of PCOS. How could they survive, and why? Normal-weight PCOS women have the same metabolic profile as healthy control. Even though they suffer from fertility problems, pregnancy is not excluded, which brings us to the idea that there might be the reasons why approximately $10 \%$ of the women population have PCOS. For the human population, especially in the times of lack (e.g. at shortage of basic food supply), it was positive to have a part of the women, which was not pregnant at the same time as the majority. There could be a reason that a combination of a genetic predisposition and environmental factors leads to the PCOS. For this reason, EDs, capable of interfering with testosterone metabolism, may form one of the supporting cause of the PCOS. During human history, the population was exposed to plenty of various forms of EDs.

To conclude, we confirmed that BPA plays a role in the PCOS. We found only low levels of BPS, slightly more frequently in PCOS patients.

We also focused on the exposure to the parabens, which was comparably low among all groups. Maintaining of the bodyweight within the normal range is essential for PCOS patients as it could protect them from most of the metabolic complications associated with this disorder. On the other hand, obesity may interfere with the actual PCOS diagnosis and, surprisingly, mitigate some of the PCOS symptomatology.

\section{Conflict of Interest}

There is no conflict of interest.

\section{Acknowledgements}

This project was supported by Ministry of Health CR, RVO (Institute of Endocrinology - EU, 00023761) and Specific university research - grant A2-FPBT_2020_017. The authors would like to thank Lukas Haberzettl for help with statistical data processing and visualization.

\section{Abbreviations}

7 $\beta$-OH-EpiA - 7ß-OH-EpiAndrosterone, 17-OH-Preg 17-OH-Pregnenolone, AMH - Anti-Müllerian Hormone, BMI - Body Mass Index, BPA - bisphenol A, BPS Bisphenol S, BPF - Bisphenol F, BPAF - bisphenol AF, BenzylP - Benzylparaben, BP - Butylparaben, DHEA Dehydroepiandrosterone, EP - Ethylparaben, FLI - Fatty Liver Index, FSH - Follicle Stimulating Hormone, G-CSF - Granulocyte Stimulating factor, HDL - HighDensity Lipoprotein, HOMA-IR - Homeostatic Model Assessment for Insulin Resistance, IL-1ra - Interleukin-1 Receptor Antagonist, IL-2 - Interleukin 2, IL-6 Interleukin 6, IL-7 - Interleukin 7, IL-13 - Interleukin 13, IFN- $\gamma$ - Interferon gamma, LH - Lutropin, LDL - LowDensity Lipoprotein, MP - Methylparaben, PDGF-bb Platelet Derived Growth Factor-BB, PP - Propylparaben, SHBG - Sex Hormone-binding Globulin, T - Testosterone, VEGF - Vascular Endothelial Growth Factor. 


\section{References}

AKGUL S, SUR U, DUZCEKER Y, BALCI A, KIZILKAN MP, KANBUR N, BOZDAG G, ERKEKOGLU P, GUMUS E, KOCER-GUMUSEL B, DERMAN O: Bisphenol A and phthalate levels in adolescents with polycystic ovary syndrome. Gynecol Endocrinol 35: 1084-1087, 2019. https://doi.org/10.1080/09513590.2019.1630608

AKIN L, KENDIRCI M, NARIN F, KURTOGLUA S, SARAYMEN R, KONDOLOT M, KOCAK SO, HATIPOGLU N: Endocrine Disruptors and Polycystic Ovary Syndrome: Phthalates. Presented at ESPE 2014 in Dublin, Endocrine Abstracts 44, P217, 2014a.

AKIN L, NARINB F, KURTOGLUA S, SARAYMEN S, KONDOLOT M, KOCAK SO, HATIPOGLU N: The Role of Bisphenol A in Etiopathogenesis of Polycystic Ovary Syndrome in Adolescent Girls. Presented at ESPE 2014, Dublin. Endocrine Abstracts, 82 P-D-1-3-229, 2014 b.

AKIN L, KENDIRCI M, NARIN F, KURTOGLUA S, SARAYMEN R, KONDOLOT M, KOCAK S, ELMALI F: The endocrine disruptor bisphenol A may play a role in the aetiopathogenesis of polycystic ovary syndrome in adolescent girls. Acta Paediatr 104: e171-e177, 2015. https://doi.org/10.1111/apa.12885

AMATO G, CONTE M, MAZZIOTTI G, LALLI E, VITOLO G, TUCKER AT, BELLASTELLA A, CARELLA CIZZO A: Serum and follicular fluid cytokines in polycystic ovary syndrome during stimulated cycles. Obstet Gynecol 101: 1177-1182, 2003. https://doi.org/10.1097/00006250-200306000-00009

ASUNCION M, CALVO RM, SAN MILLAN JL, SANCHO J, AVILA SESCOBAR-MORREALE HF: A prospective study of the prevalence of the polycystic ovary syndrome in unselected Caucasian women from Spain. J Clin Endocrinol Metab 85: 2434-2438, 2000. https://doi.org/10.1210/jc.85.7.2434

AZZIZ R, WOODS KS, REYNA R, KEY TJ, KNOCHENHAUER E, SYILDIZ BO: The prevalence and features of the polycystic ovary syndrome in an unselected population. J Clin Endocrinol Metab 89: 2745-2749, 2004. https://doi.org/10.1210/jc.2003-032046

AZZIZ R, CARMINA E, DEWAILLY D, DIAMANTI-KANDARAKIS E, ESCOBAR-MORREALE HF, FUTTERWEIT W, JANSSEN OE, LEGRO RS, NORMAN RJ, TAYLOR A EWITCHEL SF: Positions statement: criteria for defining polycystic ovary syndrome as a predominantly hyperandrogenic syndrome: an Androgen Excess Society guideline. J Clin Endocrinol Metab 91: 4237-4245, 2006. https://doi.org/10.1210/jc.2006-0178

AZZOUZ A, RASCÓN AJ, BALLESTEROS E: Simultaneous determination of parabens, alkylphenols, phenylphenols, bisphenol A and triclosan in human urine, blood and breast milk by continuous solid-phase extraction and gas chromatography-mass spectrometry. J Pharm Biomed Anal 119: 16-26, 2016. https://doi.org/10.1016/j.jpba.2015.11.024

BAKER BH, WU H, LAUE HE, BOIVIN A, GILLET V, LANGLOIS MF, BELLENGER JP, BACCARELLI A, ATAKSER L: Methylparaben in meconium and risk of maternal thyroid dysfunction, adverse birth outcomes, and Attention-Deficit Hyperactivity Disorder (ADHD). Environ Int 139: 105716, 2020. https://doi.org/10.1016/j.envint.2020.105716

BEDOGNI G, BELLENTANI S, MIGLIOLI L, MASUTTI F, PASSALACQUA M, CASTIGLIONE A, TIRIBELLI C: The Fatty Liver Index: a simple and accurate predictor of hepatic steatosis in the general population. BMC Gastroenterol 6: 33, 2006. https://doi.org/10.1186/1471-230X-6-33

BLEDZKA D, GROMADZINSKA J, WASOWICZ W: Parabens. From environmental studies to human health. Environ Int 67: 27-42, 2014. https://doi.org/10.1016/j.envint.2014.02.007

BURT SOLORZANO CM, BELLER JP, ABSHIRE MY, COLLINS JS, MCCARTNEY C, RMARSHALL JC: Neuroendocrine dysfunction in polycystic ovary syndrome. Steroids 77: 332-337, 2012. https://doi.org/10.1016/j.steroids.2011.12.007

CADAGAN D, KHAN RAMER S: Thecal cell sensitivity to luteinizing hormone and insulin in polycystic ovarian syndrome. Reprod Biol 16: 53-60, 2016. https://doi.org/10.1016/j.repbio.2015.12.006 
CUNNINGHAM T, ALLGAR V, ATKIN S, KILPATRICK E, MAGUINESS S, SATHYAPALAN T: A prospective cohort study investigating endocrine disrupting agents and polycystic ovary syndrome within an IVF setting. Presented at Society for Endocrinology BES 2016 in Brighton, Endocrine Abstracts 44 P217. https://doi.org/10.1530/endoabs.44.P217

DARBRE PD: Endocrine disruption and human health. Academic Press, 2015.

DIAMANTI-KANDARAKIS E: Polycystic ovarian syndrome: pathophysiology, molecular aspects and clinical implications. Expert Rev Mol Med 10: e3, 2008. https://doi.org/10.1017/S1462399408000598

DIAMANTI-KANDARAKIS E, PIPERI C: Genetics of polycystic ovary syndrome: searching for the way out of the labyrinth. Hum Reprod Update 11: 631-643, 2005. https://doi.org/10.1093/humupd/dmi025

DIAMANTI-KANDARAKIS E, BOURGUIGNON J-P, GIUDICE LC, HAUSER R, PRINS GS, SOTO AM, ZOELLER R, TGORE AC: Endocrine-disrupting chemicals: an Endocrine Society Scientific Statement. Endocr Rev 30: 293-342, 2009. https://doi.org/10.1210/er.2009-0002

DOMINGUEZ MA, PETRE MA, NEAL MS, FOSTER WG: Bisphenol A concentration-dependently increases human granulosa-lutein cell matrix metalloproteinase-9 (MMP-9) enzyme output. Reprod Toxicol 25: 420-425, 2008. https://doi.org/10.1016/j.reprotox.2008.05.059

DUNAIF A: Insulin resistance and the polycystic ovary syndrome: mechanism and implications for pathogenesis. Endocr Rev 18: 774-800, 1997. https://doi.org/10.1210/er.18.6.774

DUSKOVA M, KOLATOROVA L, STARKA L: Androgens in women - critical evaluation of the methods for their determination in diagnostics of endocrine disorders. Physiol Res 67 (Suppl 3): S379-S390, 2018. https://doi.org/10.33549/physiolres.933964

DUSKOVA M, KOLATOROVA L, SIMKOVA M, SRAMKOVA M, MALIKOVA M, HORACKOVA L, VITKU J, STARKA L: Steroid diagnostics of 21 st century in the light of their new roles and analytical tools. Physiol Res 69 (Suppl 2): S193-S203, 2020. https://doi.org/10.33549/physiolres.934517

EBEJER KCALLEJA-AGIUS J: The role of cytokines in polycystic ovarian syndrome. Gynecol Endocrinol 29: 536-540, 2013. https://doi.org/10.3109/09513590.2012.760195

EHRLICH S, CALAFAT AM, HUMBLET O, SMITH THAUSER R: Handling of thermal receipts as a source of exposure to bisphenol A. JAMA 311: 859-860, 2014.https://doi.org/10.1001/jama.2013.283735

EHRMANN DA: Polycystic ovary syndrome. N Engl J Med 352: 1223-1236, 2005. https://doi.org/10.1056/NEJMra041536

ELADAK S, GRISIN T, MOISON D, GUERQUIN MJ, N'TUMBA-BYN T, POZZI-GAUDIN S, BENACHI A, LIVERA G, ROUILLER-FABRE VHABERT R: A new chapter in the bisphenol A story: bisphenol $\mathrm{S}$ and bisphenol $F$ are not safe alternatives to this compound. Fertil Steril 103: 11-21, 2015. https://doi.org/10.1016/j.fertnstert.2014.11.005

ELMALID F: In the role of bisphenol A in etiopathogenesis of polycystic ovary syndrome in adolescent girls, ESPE 2014, ESPE Abstracts, 2014.

FENICHEL P, ROUGIER C, HIERONIMUS S, CHEVALIER $\mathrm{N}$ : Which origin for polycystic ovaries syndrome: Genetic, environmental or both? Ann Endocrinol (Paris) 78: 176-185, 2017. https://doi.org/10.1016/j.ando.2017.04.024

FRANKS S: Polycystic ovary syndrome. N Engl J Med 333: 853-861, 1995. https://doi.org/10.1056/NEJM199509283331307

GONZÁLEZ F: Inflammation in polycystic ovary syndrome: underpinning of insulin resistance and ovarian dysfunction. Steroids 77: 300-305, 2012. https://doi.org/10.1016/j.steroids.2011.12.003

HORNUNG RW, REED LD: Estimation of average concentration in the presence of nondetectable values. Appl Occup Environ Hyg 5: 46-51, 1990. https://doi.org/10.1080/1047322X.1990.10389587

HOSSEIN RASHIDI B, AMANLOU M, BEHROUZI LAK T, GHAZIZADEH M, HAGHOLLAHI F, BAGHERI MESLAMI B: The association between bisphenol a and polycystic ovarian syndrome: a case-control study. Acta Med Iran 55: 759-764, 2017.

HUGHESDON PE: Morphology and morphogenesis of the Stein-Leventhal ovary and of so-called "hyperthecosis". Obstet Gynecol Surv 37: 59-77, 1982. https://doi.org/10.1097/00006254-198202000-00001 
KANDARAKI E, CHATZIGEORGIOU A, LIVADAS S, PALIOURA E, ECONOMOU F, KOUTSILIERIS M, PALIMERI S, PANIDIS DDIAMANTI-KANDARAKIS E: Endocrine disruptors and polycystic ovary syndrome (PCOS): elevated serum levels of bisphenol A in women with PCOS. J Clin Endocrinol Metab 96: E480-E484, 2011. https://doi.org/10.1210/jc.2010-1658

KOLATOROVA L, SRAMKOVA M, VITKU J, VCELAK J, LISCHKOVA O, STARKA L, DUSKOVA M: Parabens and their relation to obesity. Physiol Res 67 (Suppl 3): S465-S472, 2018. https://doi.org/10.33549/physiolres.934004

KOLATOROVA SOSVOROVA L, CHLUPACOVA T, VITKU J, VLK M, HERACEK J, STARKA L, SAMAN D, SIMKOVA M, HAMPL R: Determination of selected bisphenols, parabens and estrogens in human plasma using LC-MS/MS. Talanta 174: 21-28, 2017. https://doi.org/10.1016/j.talanta.2017.05.070

KONIECZNA A, RACHON D, OWCZAREK K, KUBICA P, KOWALEWSKA A, KUDLAK B, WASIK ANAMIESNIK J: Serum bisphenol A concentrations correlate with serum testosterone levels in women with polycystic ovary syndrome. Reprod Toxicol 82: 32-37, 2018. https://doi.org/10.1016/j.reprotox.2018.09.006

LA MARCA A, ORVIETO R, GIULINI S, JASONNI VM, VOLPE A, DE LEO V: Mullerian-inhibiting substance in women with polycystic ovary syndrome: relationship with hormonal and metabolic characteristics. Fertil Steril 82: 970-972, 2004. https://doi.org/10.1016/j.fertnstert.2004.06.001

LAVEN JS, MULDERS AG, VISSER JA, THEMMEN AP, DE JONG FH, FAUSER BCJM: Anti-Mullerian hormone serum concentrations in normoovulatory and anovulatory women of reproductive age. J Clin Endocrinol Metab 89: 318-323, 2004. https://doi.org/10.1210/jc.2003-030932

LAZUROVA Z, FIGUROVA J, HUBKOVA B, LAZUROVA I: Relationship of urinary bisphenol A to metabolic and hormonal profile in PCOS women. Presented at 20th European Congress of Endocrinology, Endocrine Abstracts 56: 2018. https://doi.org/10.1530/endoabs.56.P906

LEGRO RS: Polycystic ovary syndrome and cardiovascular disease: a premature association? Endocrine Reviews 24: 302-312, 2003. https://doi.org/10.1210/er.2003-0004

LEGRO RS, KUNSELMAN AR, DODSON WC, DUNAIF A: Prevalence and predictors of risk for type 2 diabetes mellitus and impaired glucose tolerance in polycystic ovary syndrome: a prospective, controlled study in 254 affected women. J Clin Endocrinol Metab 84: 165-169, 1999. https://doi.org/10.1210/jcem.84.1.5393

MARTÍNEZ-REYES CP, GÓMEZ-ARAUZ AY, TORRES-CASTRO I, MANJARREZ-REYNA AN, PALOMERA LF, OLIVOS-GARCÍA A, MENDOZA-TENORIO E, SÁNCHEZ-MEDINA GA, ISLAS-ANDRADE S, MELENDEZ-MIER GESCOBEDO G: Serum levels of interleukin-13 increase in subjects with insulin resistance but do not correlate with markers of low-grade systemic inflammation. J Diabetes Res 2018: 7209872, 2018. https://doi.org/10.1155/2018/7209872

MATTHEWS DR, HOSKER JP, RUDENSKI AS, NAYLOR BA, TREACHER DF, TURNER RC: Homeostasis model assessment: insulin resistance and beta-cell function from fasting plasma glucose and insulin concentrations in man. Diabetologia 28: 412-419, 1985. https://doi.org/10.1007/BF00280883

MCCARTNEY CR, EAGLESON CA, MARSHALL JC: Regulation of gonadotropin secretion: implications for polycystic ovary syndrome. Semin Reprod Med 20: 317-326, 2002. https://doi.org/10.1055/s-2002-36706

NELSON VL, QIN KN, ROSENFIELD RL, WOOD JR, PENNING TM, LEGRO RS, STRAUSS JF 3RD, MCALLISTER JM: The biochemical basis for increased testosterone production in theca cells propagated from patients with polycystic ovary syndrome. J Clin Endocrinol Metab 86: 5925-5933, 2001. https://doi.org/10.1210/jcem.86.12.8088

NIEMUTH NJ, KLAPER RD: Low-dose metformin exposure causes changes in expression of endocrine disruptionassociated genes. Aquat Toxicol 195: 33-40, 2018. https://doi.org/10.1016/j.aquatox.2017.12.003

PALIOURA E, DIAMANTI-KANDARAKIS E: Industrial endocrine disruptors and polycystic ovary syndrome. J Endocrinol Invest 36: 1105-1111, 2013. https://doi.org/10.1007/BF03346762

PALIOURA E, DIAMANTI-KANDARAKIS E: Polycystic ovary syndrome (PCOS) and endocrine disrupting chemicals (EDCs). Rev Endocr Metab Disord 16: 365-371, 2015. https://doi.org/10.1007/s11154-016-9326-7

PALIOURA E, KANDARAKI E, DIAMANTI-KANDARAKIS E: Endocrine disruptors and polycystic ovary syndrome: a focus on bisphenol A and its potential pathophysiological aspects. Horm Mol Biol Clin Investig 17: 137-144, 2014. https://doi.org/10.1515/hmbci-2014-0003 
PATISAUL HB, MABREY N, ADEWALE HB, SULLIVAN AW: Soy but not bisphenol A (BPA) induces hallmarks of polycystic ovary syndrome (PCOS) and related metabolic co-morbidities in rats. Reprod Toxicol 49: 209-218, 2014. https://doi.org/10.1016/j.reprotox.2014.09.003

PIGNY P, JONARD S, ROBERT Y, DEWAILLY D: Serum anti-Mullerian hormone as a surrogate for antral follicle count for definition of the polycystic ovary syndrome. J Clin Endocrinol Metab 91: 941-945, 2006. https://doi.org/10.1210/jc.2005-2076

POLLACK AZ, MUMFORD SL, KRALL JR, CARMICHAEL A, ANDRIESSEN VC, KANNAN K, SCHISTERMAN EF: Urinary levels of environmental phenols and parabens and antioxidant enzyme activity in the blood of women. Environ Res 186: 109507, 2020. https://doi.org/10.1016/j.envres.2020.109507

ROCHESTER JR, BOLDEN AL: Bisphenol S and F: a systematic review and comparison of the hormonal activity of bisphenol A substitutes. Environ Health Perspect 123: 643-650, 2015. https://doi.org/10.1289/ehp.1408989

Rotterdam ESHRE/ASRM-Sponsored PCOS Consensus Workshop Group: Revised 2003 consensus on diagnostic criteria and long-term health risks related to polycystic ovary syndrome. Fertil Steril 81: 19-25, 2004. https://doi.org/10.1016/j.fertnstert.2003.10.004

RUTKOWSKA A, KONIECZNA A, WILCZEWSKA K, CIECHANOWICZ A, CZERNYCH R, RACHON D: The commonly used plasticisers (bisphenols and phthalates) as endocrine disrupting chemicals in healthy women and women with polycystic ovary syndrome. Presented at 17th European Congress of Endocrinology, Dublin 2015, Endocrine Abstracts 37, 2015. https://doi.org/10.1530/endoabs.37.EP209

SCHMIDT FM, WESCHENFELDER J, SANDER C, MINKWITZ J, THORMANN J, CHITTKA T, MERGL R, KIRKBY KC, FAßHAUER M, STUMVOLL M, HOLDT LM, TEUPSER D, HEGERL UHIMMERICH H: Inflammatory cytokines in general and central obesity and modulating effects of physical activity. PLoS One 10: e0121971-e0121971, 2015. https://doi.org/10.1371/journal.pone.0121971

SIMKOVA M, TICHY T, DUSKOVA M, BRADNA P: Dental composites - a low-dose source of bisphenol A? Physiol Res 69 (Suppl 2): S295-S304, 2020. https://doi.org/10.33549/physiolres. 934518

TAKEUCHI T, TTSUTSUMI O: Serum bisphenol a concentrations showed gender differences, possibly linked to androgen levels. Biochem Biophys Res Commun 291: 76-78, 2002. https://doi.org/10.1006/bbrc.2002.6407

TAKEUCHI T, TSUTSUMI O, IKEZUKI Y, TAKAI Y, TAKETANI Y: Positive relationship between androgen and the endocrine disruptor, bisphenol A, in normal women and women with ovarian dysfunction. Endocr J 51: 165-169, 2004. https://doi.org/10.1507/endocri.51.165

VAGI SJ, AZZIZ-BAUMGARTNER E, SJODIN A, CALAFAT AM, DUMESIC D, GONZALEZ L, KATO K, SILVA MJ, YE XAZZIZ R: Exploring the potential association between brominated diphenyl ethers, polychlorinated biphenyls, organochlorine pesticides, perfluorinated compounds, phthalates, and bisphenol A in polycystic ovary syndrome: a case-control study. BMC Endocr Disord 14: 86, 2014. https://doi.org/10.1186/1472-6823-14-86

VAHEDI M, SAEEDI A, POORBAGHI SL, SEPEHRIMANESH M, FATTAHI M: Metabolic and endocrine effects of bisphenol A exposure in market seller women with polycystic ovary syndrome. Environ Sci Pollut Res Int 23: 23546-23550, 2016. https://doi.org/10.1007/s11356-016-7573-5

VELA-SORIA F, RODRÍGUEZ I, BALLESTEROS O, ZAFRA-GÓMEZ A, BALLESTEROS L, CELA RNAVALÓN A: Simplified matrix solid phase dispersion procedure for the determination of parabens and benzophenoneultraviolet filters in human placental tissue samples. J Chromatogr A 1371: 39-47, 2014. https://doi.org/10.1016/j.chroma.2014.10.063

VERMEULEN A, VERDONCK L, KAUFMAN JM: A critical evaluation of simple methods for the estimation of free testosterone in serum. J Clin Endocrinol Metab 84: 3666-3672, 1999. https://doi.org/10.1210/jcem.84.10.6079

VITKU J, CHLUPACOVA T, SOSVOROVA L, HAMPL R, HILL M, HERACEK J, BICIKOVA M, STARKA L: Development and validation of LC-MS/MS method for quantification of bisphenol A and estrogens in human plasma and seminal fluid. Talanta 140: 62-67, 2015. https://doi.org/10.1016/j.talanta.2015.03.013

VITKU J, KOLATOROVA L, FRANEKOVA L, BLAHOS J, SIMKOVA M, DUSKOVA M, SKODOVA T, STARKA L: Endocrine disruptors of the bisphenol and paraben families and bone metabolism. Physiol Res 67 (Suppl 3): S455-S464, 2018a. https://doi.org/10.33549/physiolres.934005 
VITKU J, KOLATOROVA L, RICCO C, FERROUD C, HENNEBERT O, SKODOVA T, HERACEK J, STARKA L: The quantitation of 7beta-hydroxy-epiandrosterone in the plasma and seminal plasma of men with different degrees of fertility. Physiol Res 67 (Suppl 3): S511-S519, 2018b. https://doi.org/10.33549/physiolres.933963

WANG R, MOL BWJ: The Rotterdam criteria for polycystic ovary syndrome: evidence-based criteria? Hum Reprod 32: 261-264, 2017. https://doi.org/10.1093/humrep/dew287

WANG Y, ZHU Q, DANG X, HE Y, LI X, SUN Y: Local effect of bisphenol A on the estradiol synthesis of ovarian granulosa cells from PCOS. Gynecol Endocrinol 33: 21-25, 2017. https://doi.org/10.1080/09513590.2016.1184641

WEBBER LJ, STUBBS S, STARK J, TREW GH, MARGARA R, HARDY K, FRANKS S: Formation and early development of follicles in the polycystic ovary. Lancet 362: 1017-1021, 2003. https://doi.org/10.1016/S0140$\underline{6736(03) 14410-8}$

WELSHONS WV, NAGEL SC, VOM SAAL FS: Large effects from small exposures. III. Endocrine mechanisms mediating effects of bisphenol A at levels of human exposure. Endocrinology 147: S56-S69, 2006. https://doi.org/10.1210/en.2005-1159

WIJEYARATNE CN, SENEVIRATNE R DE A, DAHANAYAKE S, KUMARAPELI V, PALIPANE E, KURUPPU N, YAPA C, SENEVIRATNE R DE A, BALEN AH: Phenotype and metabolic profile of South Asian women with polycystic ovary syndrome (PCOS): results of a large database from a specialist Endocrine Clinic. Hum Reprod 26: 202-213, 2011. https://doi.org/10.1093/humrep/deq310

XIONG YL, LIANG XY, YANG X, LI Y, WEI LN: Low-grade chronic inflammation in the peripheral blood and ovaries of women with polycystic ovarian syndrome. Eur J Obstet Gynecol Reprod Biol 159: 148-150, 2011. https://doi.org/10.1016/j.ejogrb.2011.07.012

YANG Z, SHI J, GUO Z, CHEN M, WANG C, HE C, ZUO Z: A pilot study on polycystic ovarian syndrome caused by neonatal exposure to tributyltin and bisphenol $A$ in rats. Chemosphere 231: 151-160, 2019. https://doi.org/10.1016/j.chemosphere.2019.05.129

ZAWADZKI J, DUNAIF A: Current issues in endocrinology and metabolism: polycystic ovary syndrome. Blackwell Scientific Publications Cambridge, MA, 1992.

ZHOU W, FANG F, ZHU W, CHEN ZJ, DU Y, ZHANG J: Bisphenol A and ovarian reserve among infertile women with polycystic ovarian syndrome. Int $\mathrm{J}$ Environ Res Public Health 14: 18, 2016. https://doi.org/10.3390/ijerph14010018

ŽALMANOVÁ T, HOŠKOVÁ K, NEVORAL J, PROKEŠOVÁ Š, ZÁMOSTNÁ K, KOTT T, PETR J: Bisphenol S instead of bisphenol A: a story of reproductive disruption by regretable substitution - a review. Czech $\mathrm{J}$ Anim Sci 61: 433-449, 2016. https://doi.org/10.17221/81/2015-CJAS 